\title{
Role of TRP channels in the induction of heat shock proteins (Hsps) by heating skin
}

\author{
Wen-Li Hsu ${ }^{1,2}$ and Tohru Yoshioka ${ }^{1}$ \\ ${ }^{1}$ Graduate Institute of Medicine, School of Medicine, Kaohsiung Medical University, 100, Shih-Chuan 1st Road, Kaohsiung 80708, Taiwan \\ ${ }^{2}$ The Institute of Basic Medical Sciences, National Cheng Kung University Medical College, 1 University Road, Tainan 70101, Taiwan
}

Received December 17, 2014; accepted January 7, 2015

Transient receptor potential (TRP) channels in skin are crucial for achieving temperature sensitivity to maintain internal temperature balance and thermal homeostasis, as well as to protect skin cells from environmental stresses such as infrared (IR) or near-infrared (NIR) radiation via heat shock protein (Hsp) production. However, the mechanisms by which IR and NIR activate TRP channels and produce Hsps intracellularly have been independently reported. In this review, we discuss the relationship between TRP channel activation and Hsp production, and introduce the roles of several skin TRP channels in the regulation of HSP production by IR and NIR exposure.

Key words: Heat shock protein, infrared, near infrared, skin, TRP channel

Despite a huge number of studies on the transient receptor potential (TRP) superfamily of cation channels and heat shock proteins (Hsps), a direct relationship between TRP channel activation and Hsp induction is not independently reported. TRP channels were discovered initially in Drosophila retina [1] and were investigated mainly in the fields of sensory transduction and biological sciences. More recently, TRP channel studies have focused largely on mechanosensation, cell signaling, aging, and cancer research [1-4]. Among the many kinds of thermosensitive TRP channels that are well known to exist in human skin [5], there have

Corresponding author: Tohru Yoshioka, Visiting Professor, Graduate Institute of Medicine, School of Medicine, Kaohsiung Medical University, 100, Shih-Chuan 1st Road, Kaohsiung 80708, Taiwan.

e-mail: yoshitohru@gmail.com been few studies on TRP channels or Hsps [6-8]. However, many kinds of thermosensitive TRP channels are activated by heat, potentially inducing Hsps to respond to a wide variety of physiological and environmental insults. Mammalian TRP channels consist of six-transmembrane (6-TM) cationpermeable channels that are classified into six subfamilies based on amino acid sequence homology: TRPC, TRPV, TRPM, TRPP, TRPA, and TRPML [1]. The functional properties of these six subfamilies of TRP channels are listed and exhibited elsewhere [9]. Four heat-activated channels, TRPV1-4, and two cold-activated channels, TRPM8 and TRPA1, belong to temperature-sensitive transient receptor potential channels, and are expressed in dorsal root ganglion sensory neurons, skin, and other cells [10]. Temperature sensitivity is crucial to protect against skin damage as well as to maintain internal temperature balance or thermal homeostasis [5]. Thermo TRP channels, TRPV1,3,4, TRPM8, and TRPA1, are known to be expressed in human keratinocytes (KCs); two of them, TRPV1 and TRPA1, are expressed in human skin fibroblasts (HDFs) [1,5], which are major regulators of skin cell proliferation and differentiation, in the skin barrier, and in immune functions responding to skin injury [5]. Furthermore, environmental stress in the skin also induces Hsp production, which plays an important role in triggering some molecular mechanisms involved in damage recovery. According to the review by Kregel [11], the numerous findings on the physiological functions of Hsps against damage can be summarized as follows. The proposed functions of each Hsp are (a) microfilament stabilization and anti-apoptotic effect by Hsp27, (b) refolding of proteins and aggregation of denatured proteins by Hsp 60, (c) cytoprotection due to protein folding by Hsp 70, (d) regulation of steroid hormone receptor and protein translocation by 
Hsp90, (e) protein folding by Hsp 110/104 [12]. Among the inducers of the heat shock response for protecting skin from damage, environmental stresses such as temperature and solar rays (ultraviolet, UV and infrared, IR) are the most efficient agents to produce Hsps in human skin, but the effect of IR (including near-infrared, NIR) on Hsp induction has not been well studied. Therefore, NIR and IR are the most interesting means of producing Hsps in human skin. How do IR and NIR activate TRP channels? How do IR and NIR facilitate the production of Hsps intracellularly? What is the relationship between TRP channel activation and Hsp production? To answer these questions, this review focuses on IR and NIR exposure to produce Hsps by the activation of TRP channels in the skin cell.

\section{Reactive oxygen species (ROS) production by electromagnetic waves, including IR and NIR}

ROS is generally produced by ionizing radiation and the excitation of water molecules by light. When living tissue is exposed to radiation, including gamma and X-rays, water molecules in the tissue are ionized to make hydrated electrons, leading to the formation of superoxide radicals, hydroxyl radicals, and other free radicals. In the case of UV rays and visible light, the ground state of water molecules is excited and then hydroxyl radicals are mainly produced. On the other hand, when the tissue is heated by external microwave (EMW), which is called hyperthermia, hydroxyl radicals are produced efficiently in the tissue (Fig. 1) [13]. The following section describes how electromagnetic waves produce ROS with wavelength dependence.

\section{Ultraviolet-B (UVB)-induced ROS production in skin}

Among exogenous harmful UV rays, UVB $(290 \mathrm{~nm} \sim$ $320 \mathrm{~nm}$ ) plays the most valuable role in the field of photodynamic therapy (PDT) [14]. UVB is also evaluated in the clinical field, such as clinical sunburn, hyperpigmentation, erythema, plaque-like thickening, loss of skin tone, deep furrowing, and wrinkle formation [15]. UVB-induced skin damage and carcinogenesis are also due to the ROSdependent depletion of several protein functions, which will lead to senescence, differentiation, and connective tissue degradation [16]. According to our recent findings (unpublished data), the molecular mechanism underlying UVB's toxic effect was clearly elucidated. As is well known, KCs possess several types of TRP channels, such as TRPC7, TRPV1, TRPV3, TRPV4, TRPM8, and TRPA1. Among them, TRPV1 and TRPA1 were found to be sensitive to ROS, including free radicals. And in human skin, HDFs are equipped with TRPV1 and TRPA1, both of which are sensitive to ROS. It is very reasonable to assume that ROS can open TRP channels $[17,18]$. When a TRP channel is open, $\mathrm{Ca}^{2+}$ and $\mathrm{Na}^{+}$enter the cytosol from extracellular space. The increased $\mathrm{Ca}^{2+}$ in the cytosol activates the mitochondrial TCA cycle, which then generates ATP as well as ROS [19].

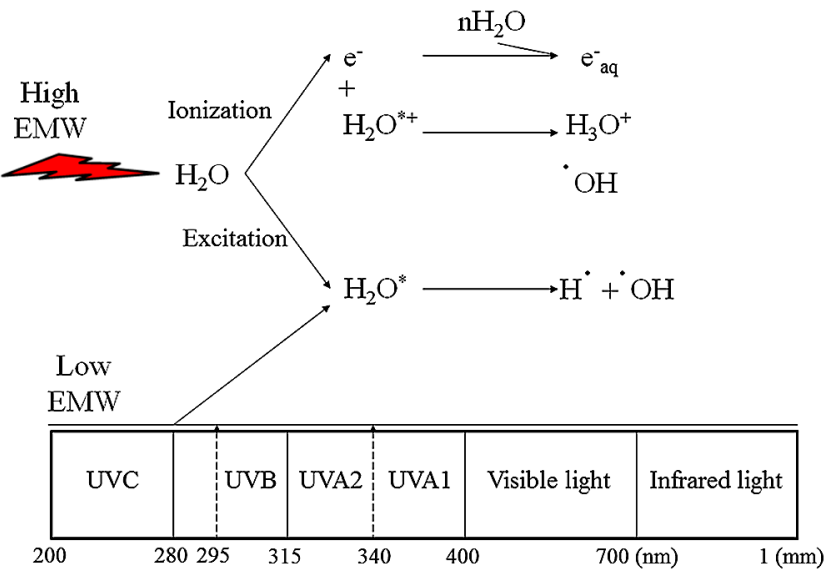

Figure 1 Different ways to produce reactive oxygen species (ROS) using different types of external microwave (EMW).

The ROS produced in the mitochondria damage induces Hsps in the cell. Consequently, as ROS is generated anywhere in the cell, the cell could be injured. It is possible that the Hsps provide ameliorative effects through their molecular chaperone, cytoprotective, and anti-inflammatory properties against ROS-induced damage in the skin [15,20-22].

\section{High-temperature treatment}

There are three ways to heat up living tissue: soaking of the tissue in a high-temperature water bath, IR exposure, and millimeter (high-frequency) microwave irradiation to the body. The water bath method is the easiest method, while the microwave method is problematic: intermittent hightemperature exposure to the whole body is difficult to achieve, and homeostasis prevents control over the temperature of the interior part of the body. For IR rays to be more useful in the human body, they must reach deeper than about $2 \mathrm{~cm}$ beneath the skin surface. However, the main disadvantage of IR ray is to become too scattered in the tissue, making it impossible to specify the high-temperature region in the skin and measure temperature of the internal region of animal body except phantom model. The same situation occurs in the case of micrometer waves (MMWs). When a MMW irradiates living tissue, the high-frequency $(>1 \mathrm{GHz})$ wave oscillates water molecules vigorously, and the resulting friction with other molecules in the body produces heat.

As described previously, high-temperature treatment of living tissue induces ROS production. In KCs, for example, there are five heat-sensitive TRP channels: TRPV1, TRPV3, TRPV4, TRPA1, and TRPM8. It has already been established that each channel covers different temperature ranges, but the underlying heat-sensitive mechanism is unknown (Fig. 2). Interestingly, the temperature-dependent coefficient $\left(Q_{10}\right)$ value of the responses is about 40 , an exceptionally high value for temperature changes [23]. Once the TRP channel is open, mitochondrial complexes I and II are activated via the elevation of intra-mitochondrial $\mathrm{Ca}^{2+}$, after 


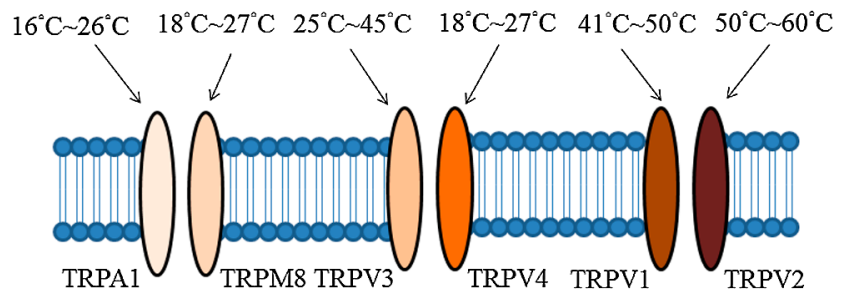

\begin{tabular}{lcc} 
Protein & $\mathrm{T}_{\text {range }}{ }^{\circ} \mathrm{C}$ & $\mathrm{Q}_{10}$ \\
\hline TRPA1 & $26-16$ & $\approx 10$ \\
TRPM8 & $27-18$ & 24 \\
& & \\
TRPV1 & $41-50$ & 40 \\
TRPV2 & $50-60$ & $>100$ \\
TRPV3 & $24-34$ & 33 \\
TRPV4 & $25-45$ & 10,19
\end{tabular}

Figure 2 Effects of heat exposure on the characteristics of TRPV1 channel.

which ROS is released from it intracellularly [24,25]. Unfortunately, the heat-sensitive mechanism of TRP channels has not been clarified completely. Recently, Voets et al. proposed a "two-state model" for temperature-sensitive channel gating for the TRPV1 channel; the channel is activated upon membrane depolarization, and the voltage dependence of activation is highly sensitive to temperature [26,27]. The schematic model of the strong temperature dependence of a thermossensitive TRP channel is $\sim 1$ equivalent charge per channel, less than the $\sim 14$ equivalent charges in a shakertype voltage-gated $\mathrm{K}^{+}$channel. Although the two-state model is probably the simplest scheme to describe the temperature effect of channel opening, it also accurately describes temperature and voltage dependence. Accordingly, we do not hesitate to adopt the two-state theory as an appropriate model in the present stage. As a result, we can explain how the generation of ROS by hyperthermia is highly dependent on the distribution of thermosensitive TRP channels.

\section{NIR- and IR-induced ROS production in skin}

NIR and IR possess two-sidedness for ROS production: one is as a heat carrier to activate thermosensitive TRP channels $[28,29]$; the other is the way to make singlet oxygen, a precursor of free radicals, by the activation of several molecules [30,31]. Singlet oxygen production is sometimes called a nonthermal effect, which is known to result in DNA damage and cell death by directly attacking functional proteins [32]. Also, NIR irradiation is adopted as a therapeutic option for the treatment of wound healing disorders [33]. The IR spectral region is divided into three categories: NIR (760 $3,000 \mathrm{~nm})$, IR $(3,000 \sim 30,000 \mathrm{~nm})$, and far IR $(30,000 \mathrm{~nm} \sim$ $1 \mathrm{~mm}$ ). Among them, NIR wavelength, shorter than $1,100 \mathrm{~nm}$ and longer than $1,850 \mathrm{~nm}$, can reach deeper $(>2 \mathrm{~cm})$ tissues [34], because in a specific range of wavelengths $(1,100 \mathrm{~nm}<$ wave length $<1,450 \mathrm{~nm}$ ) will be absorbed largely by water molecules. The survival wavelength of NIR can cause photochemical changes and induce several kinds of damage in the tissue. However, it was very difficult to get direct evidence that singlet oxygen is generated in water, because in $\mathrm{H}_{2} \mathrm{O}$ the mean lifetime of singlet oxygen was very short, $\sim 3.5 \mu$ seconds. Recently, singlet oxygen was detected in water by the use of two photons of IR [35].

\section{Activation and inhibition of TRP channels}

Among several kinds of TRP channels, it is easy to conjecture that the TRPV family is distributed in human skin. In addition, both TRPM8 and TRPA1 are expressed in the skin as temperature sensors. Furthermore, although the TRPC family does not belong to thermosensitive TRP channels, it controls calcium entry under epidermal receptor stimulation, which is an important part of a functional system for maintaining skin homeostasis [36]. Therefore, in the following section we summarize the role of TRP channels in the skin [5].

\section{TRPV subfamily}

Among the six subfamilies of TRPV channels, TRPV1, TRPV3, and TRPV4 are known to be found in skin cells, especially in KCs. TRPV1-type channels are activated by heat, low $\mathrm{pH}$, and pro-inflammation [1]. It was also reported that TRPV1-type channels are sensitive to some physical stresses such as high $\left(>42^{\circ} \mathrm{C}\right)$ temperature, membrane stretching, and several chemicals (ethanol, lidocaine, monoacylglycerols, and 2-Aminoethoxydiphenyl borate, 2APB) [37]. Ion selectivity, which is expressed as $\mathrm{PCa} / \mathrm{PNa}$, is approximately 10 for chemical stimulation and 4 for physical stimulation [1]. TRPV1 is also expressed in dermal fibroblast [38]. The TRPV1 channel in skin was found to be essential for the control of skin growth as well as for barrier functions, cutaneous immunological functions, skin pathology and several cutaneous diseases [5], and skin aging [38]. It is worth noting that TRPV1 can be activated directly by OAG, a membrane-permeable diacylglycerol (DAG) analog, although the 1-oleoyl-2-acetyl-sn-glycerol (OAG)-induced calcium response is one-fifth of the capsaicin-induced signal [39]. The activation of TRPV1 by membrane-permeable OAG does not mean it is activated by $\mathrm{G}$ protein-coupled receptor (GPCR), because DAG produced by the hydrolysis of phosphatidylinositol 4,5-bisphosphate ( $\mathrm{PIP}_{2}$ ) by phospholipase $\mathrm{c}$ (PLC) $\beta$ is phosphorylated to phosphatidic acid (PA) by DAG kinase immediately [40]. Interestingly, $\mathrm{PIP}_{2}$ appears to bind to the TRPV1 channel directly, causing channel inhibition that is relieved by PLC $\beta$-catalyzed PIP ${ }_{2}$ hydrolysis. The C-terminal of TRPV1 transcription disrupts the $\mathrm{PIP}_{2}$ binding site and impairs thermal responsiveness. Moreover, TRPV3 is sensitive to warm temperature $\left(33^{\circ} \mathrm{C}-39^{\circ} \mathrm{C}\right)$, and $\mathrm{PCa} / \mathrm{PNa}$ is around 3. Heat-activated TRPV3 current displays strong outward rectification, striking thermal hystere- 
sis, and sensitization following repeated activation [41]. The TRPV3 channel's roles in the skin include nociception, skin integrity, wound healing, hair growth, and sebocyte functions. Similar to the TRPV3 channel, the TRPV4 channel covers a temperature range $\left(27^{\circ} \mathrm{C}-34^{\circ} \mathrm{C}\right)$, and the ratio of $\mathrm{PCa} / \mathrm{PNa}$ is close to 6. Unlike TRPV1-TRPV3, TRPV4 is apparently insensitive to activation by $2 \mathrm{APB}[42,43]$. The TRPV4 channel is involved in mechano-sensation, osmosensation, nociception, modulation of cell migration, the shear stress sensor, and control adherence junction in the skin cochlea [44].

\section{TRPA1}

TRPA1, well known as a noxious cold pain sensor, is also expressed highly in KCs [45] and in HDFs [44]. Interesting, the role of this channel may be essentially different from those of other TRPV channels, because it is directly activated by intracellular $\mathrm{Ca}^{2+}$ through binding to the $\mathrm{N}$-terminal EF-hand domain of TRPA1 [46]. This mechanism underlying this action was suggested to be activation and/or sensitization of TRPA1 channels by GPCR coupled to PLC $\beta$ signaling, such as bradykinin receptors [47]. In addition, since TRPA1 is involved in inflammatory pain (increased sensitivity to painful stimuli), TRPA1 may underlie some components of inflammatory hyperalgesia (increased sensory neurons for cold hyperalgesia). Thus, TRPA1 is most likely a chemical sensor for injury and inflammation [48]. Many TRPA1 ligands, such as mustard oil, acrolein, formalin, and iodoacetamide, can activate TRPA1 extracellularly, while acetaldehyde, $\mathrm{H}_{2} \mathrm{O}_{2}, 15 \mathrm{~d}$-prostaglandin $\mathrm{J} 2$, and prostaglandin A2 (PGA2), all of which are called reactive electrophilic species (RES), work intracellularly [49]. These RESs are generated under oxidative stress with the chemical reactivity being transferred from ROS to RES [49]. It is likely that these ROS promote disulfide formation between vicinal thiol residues, resulting in TRPA1 dysfunction [49]. However, TRPA1 activation is recovered by the application of dithiothreitol (DTT), which reduces the disulfide bond to the -SH group of cysteine in TRPA1 [50].

The sensitivity of TRPA1 to intracellular $\mathrm{Ca}^{2+}$ and ROS accelerates cell depolarization, which will activate voltagedependent $\mathrm{Ca}^{2+}$ channels, leading to skin aging, carcinogenesis, and apoptosis [51]. Thus, TRPA1 may help regulate the proliferation and differentiation of KCs and skin inflammation [52]. Some functional properties of TRPA1 depend on its ability to interact with TRPV1. The coexistence of TRPA1 with TRPV1 seems to be important for the action of an endogenous mediator, such as bradykinin or calcium [53]. Interestingly, Akopian et al. also found that TRPV1 can regulate the mediator of TRPA1 by $\mathrm{Ca}^{2+}$ through the $\mathrm{PIP}_{2}$ signaling pathway [54]. Thus, the physiological functions of TRPA1 are summarized as follows: thermo-sensation, the most versatile chemo-sensor, mechanical sensation (?), nociception and, interestingly, olfactory transduction [44].

\section{TRPM8}

The TRPM channel controls certain skin functions, especially those related to melanocyte biology. TRPM8 displays a cold receptor of the body, and its activation can be modulated by many cooling compounds and many other odorant agents isolated from plants, e.g., linalool, geraniol, and hydroxycitronellal $[55,56]$; and the selectivity of $\mathrm{Ca}^{2+}$ is about three times higher than that of $\mathrm{Na}^{+}$[1]. These results were confirmed electrophysiologically using whole-cell patch clamp experiments [26]. It was also confirmed that the TRPM8 channel was activated by depolarization, which means that the TRPM8 channel is very sensitive to changes in the cell's ionic balance. Thus it is natural to consider that the TRPM8 channel is involved in body temperature regulation [57].

\section{TRPC6 and TRPC7}

The TRPC subfamily was established as the first recognized mammalian TRP channel [58]. According to the results obtained by Sakura et al., the TRPC subfamily is divided into three groups on the basis of sequence alignments: TRPC1/4/5, TRPC3/6/7, and TRPC2 [59]. TRPC1/4/5/7 channels are expressed in $\mathrm{HaCaT}$, an immortal human keratinocyte line [60], while Cai et al. detected TRPC1/C5/C6/ $\mathrm{C} 7$ in gingival KCs [61]. TRPC7 is also a receptor-operated, DAG-activated channel in KCs, mediating a PLC $\beta 4$ activated transducer current in intrinsic photosensitivity $[36,62]$. Consequently, we focus here only on TRPC 7, based on the newest results published by Beck [60]. As was previously described, most of the TRPC subfamily shows similar characteristics for activation by DAG and inhibition by SKF96365. Thus, it is reasonable to discuss the characteristics of TRPC6 and TRPC7 as representative of the TRPC subfamily in $\mathrm{KCs}$, since these channels are activated by membrane-permeable DAG [60]. And Muller et al. suggested that TRPC6 is a specific channel for inducing KCs differentiation [63]. Eventually, several members of the canonical TRPC subfamily were identified in the skin, where they mostly control the growth and differentiation of KCs under physiological and pathological conditions [5]. After all, these TRPC channels in the skin are considered to be significantly involved in skin cell growth, barrier function, and cutaneous diseases. Based on the above discussion, as TRP channel open through oxidative stress, intracellular calcium elevation induces ROS and ATP production in mitochondria resulting in disulfide bonds formation to protein dysfunction. A scenario is shown in Figure 3.

\section{Hsp formation in skin cells}

Among several mechanisms that ensure the survival of cells, the most conserved mechanism of cellular protection is the expression of Hsps $[15,64]$. This protection has been called "stress tolerance", because constitutive Hsps are involved in protein folding and are translocated across the 
TRP channel open
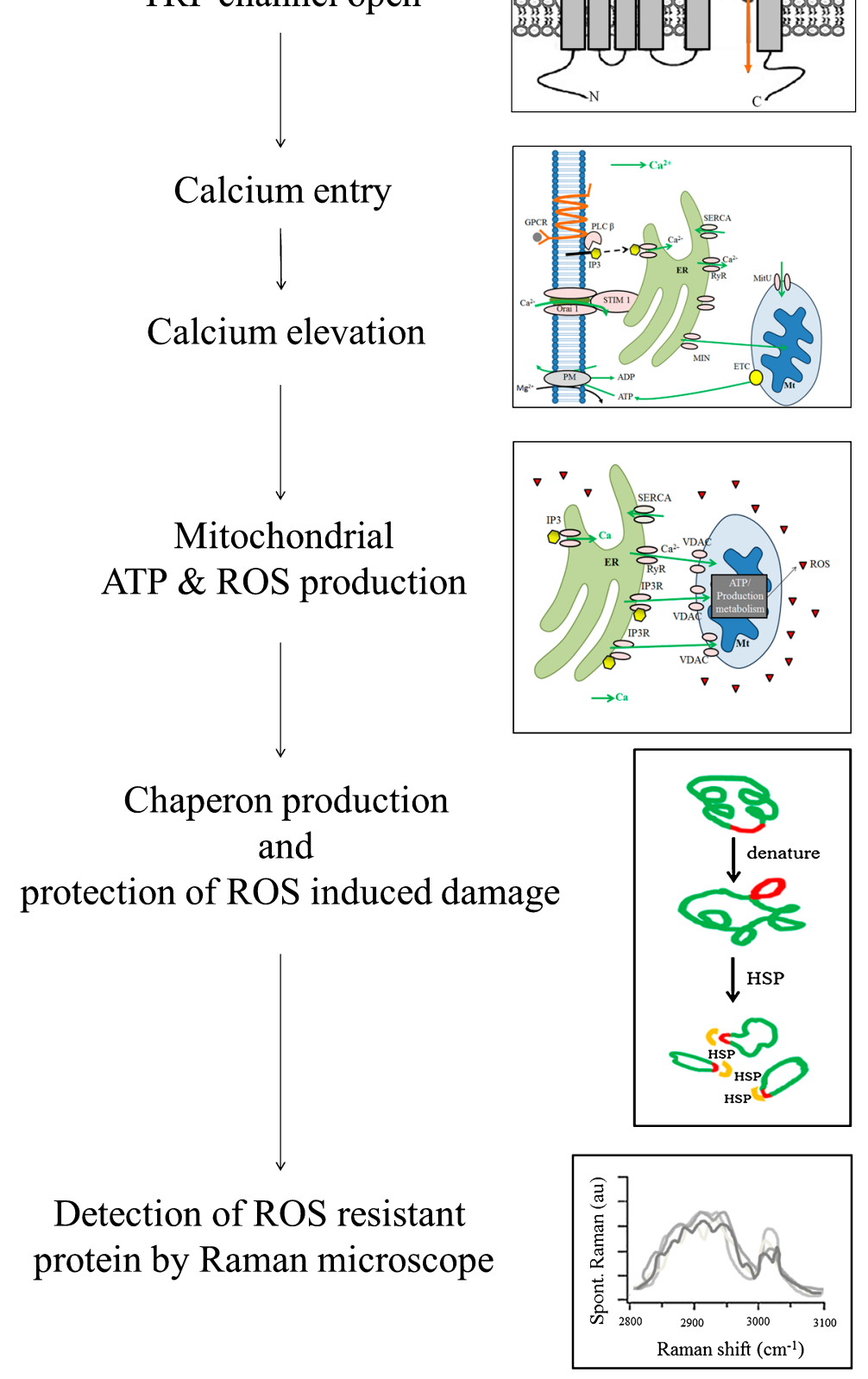

Figure 3 Scenario in which ROS produce heat shock protein (Hsp). Abbreviations: S, sulfide bond; GPCR, G protein-coupled receptor; PM, plasma membrane; PLC $\beta$, phospholipase $\mathrm{C}$ beta; $\mathrm{IP}_{3}$, inositol 1,4,5-trisphosphate; SERCA, sarco/endoplasmic reticulum calcium transport ATPase; RyR, ryanodine receptor; MIN, mini volume of calcium; ETC, electron transport chain; VDAC, voltage-dependent anion channels; MitU, mitochondria; unfolded protein response induced calcium signal.

membrane as "molecular chaperones" [65]. So far, a large number of Hsps have been identified as Hsp27, Hsp33, Hsp60, Hsp70, Hsp90, and Hsp110 [11]. It was reported that Hsp27, Hsp60, Hsp70, and Hsp90 are expressed in KCs. In the following sections we discuss these questions: how are Hsps induced? Is calcium involved in Hsp induction? How are ROS and TRP channels involved in Hsp production?

\section{Direct induction of Hsps by oxidative stress}

Hsps are expressed in response to any kind of stress signal that compromises cell survival. In mammals, Hsps are expressed when body temperature is above $41^{\circ} \mathrm{C}$. Thus irradiation of IR or NIR induces the increased expression of Hsps, especially Hsp70 in skin [66,67]. Besides, not only rising body temperature but also heavy metals (As, Cd), ethanol, oxygen radicals, and peroxides are agents that can 
induce heat-shock responses [68]. Based on these data, Gabriele Multhoff proposed that the real inducer of Hsps is the presence of denatured proteins within the cell [69]. This hypothesis was supported by experiments in which heatshock responses were also induced by microinjection of denatured protein into the cells [70]. Another example of Hsp production was observed in an animal experiment by ischemia and reperfusion in the liver, brain, heart, and kidney [70]. This also explains that Hsp production is closely related to oxidative stress effect, which is increased during both ischemia and reperfusion [71,72]. However, ROS generation such as that by $\mathrm{H}_{2} \mathrm{O}_{2}$ and hydroxyl radicals can lead to irreversible protein damage, side-chain oxidation, nonspecific disulfide bond formation, thermal instability, aggregation, and finally cell death $[73,74]$. After all, it is reasonable to consider that Hsps and ROS are two sides of the same coin [75].

\section{Calcium and Hsps}

According to the proposal of Kiang and Tsokos [76], Hsp expression is modulated by cell signal transducers, such as changes in intracellular $\mathrm{pH}, \mathrm{cAMP}, \mathrm{Ca}^{2+}, \mathrm{IP}_{3}, \mathrm{PKC}$, and protein phosphatases. Actually, increases in intra-cellular $\mathrm{Ca}^{2+}$ greatly attenuate the translocation of heat-shock transcription factor (HSF) from cytosol to nucleus, Hsp gene expression, and protein synthesis. $\mathrm{IP}_{3}$ is important in the regulation of Hsp protein expression, because treatment with pertussis toxin, cholera toxin, and forskolin increased $\mathrm{IP}_{3}$ production, which led to the increased gene level of Hsp in human epidural cells. In contrast, an inhibitor of $\mathrm{IP}_{3}$ production diminishes the heat-induced expression of Hsps [77,78]. This is supported by the finding that the binding of $\mathrm{IP}_{3}$ to its receptor of ER alters RNA splicing and regulates the expression of multiple gene products [79]. The involvement of PKC and phosphoprotein phosphatase is also confirmed. Together, the previous results suggest that calcium signaling is also important to understand the molecular mechanism by which heat produces Hsps. It is not so easy to combine hyperthermia and $\mathrm{IP}_{3}$-induced calcium signaling, but it will be possible if we assume that the involvement of TRP channels in the hyperthermis induces Hsp production.

\section{A tentative model of Hsp production by heat}

We discuss the roles of several skin TRP channels in the regulation of Hsps production via increased intracellular calcium induced ROS generation after IR and NIR exposure. Thus, the coexistence of TRPV1 and TRPA1 potentially supports a model to explain how hyperthermia can produce Hsps in the cell. This coexistence fulfills the necessary and sufficient conditions to produce Hsps; for Hsp production in the nucleus, an $\mathrm{IP}_{3}$ signal is needed. For $\mathrm{IP}_{3}$ production, PLC $\beta$ must be activated; the Nishizuka school has already established that a rapid increase in $\mathrm{Ca}^{2+}$ is enough for PLC $\beta$ activation in vitro. Also for in vivo study, a conditional tissue specific knockout mice are established, blocking TRPV1 or
TRPA1 in skin to further detect the production of Hsps after IR/NIR exposure. Therefore, we hypothesize that the activation of TRP channels induces several types of Hsp proteins via intracellular calcium elevation to protect human skin (the largest organ of the human body) and maintain skin homeostasis from harmful EMW and high temperature.

\section{Conflict of Interest}

None of the authors have any conflict of interest to report.

\section{Author Contributions}

W. H. and T. Y. co-wrote the manuscript.

\section{References}

[1] Venkatachalam, K. \& Montell, C. TRP channels. Ann. Rev. Biochem. 76, 387-417 (2007).

[2] Veldhuis, N. A., Poole, D. P., Grace, M., McIntyre, P. \& Bunnett, N. W. The G protein-coupled receptor-transient receptor potential channel axis: molecular insights for targeting disorders of sensation and inflammation. Pharmacol. Rev. 67, 36-73 (2015).

[3] Holzer, P. \& Izzo, A. A. The pharmacology of TRP channels. Br. J. Pharmacol. 171, 2469-2473 (2014).

[4] Christensen, A. P. \& Corey, D. P. TRP channels in mechanosensation: direct or indirect activation? Nat. Rev. Neurosci. 8 , 510-521 (2007).

[5] Toth, B. I., Olah, A., Szollosi, A. G. \& Biro, T. TRP channels in the skin. Br. J. Pharmacol. 171, 2568-2581 (2014).

[6] Kampinga, H. H. Cell biological effects of hyperthermia alone or combined with radiation or drugs: a short introduction to newcomers in the field. Int. J. Hyperthermia 22, 191-196 (2006).

[7] Miller, M. W. \& Ziskin, M. C. Biological consequences of hyperthermia. Ultrasound Med. Biol. 15, 707-722 (1989).

[8] Aleksandrov, V. \& Kisliuk, I. M. The cellular reaction to heat shock: the physiological aspect. Tsitologiia 36, 5-59 (1994).

[9] Zheng, J. Molecular mechanism of TRP channels. Compr. Physiol. 3, 221-242 (2013).

[10] Clapham, D. E. TRP channels as cellular sensors. Nature $\mathbf{4 2 6}$ 517-524 (2003)

[11] Kregel, K. C. Heat shock proteins: modifying factors in physiological stress responses and acquired thermotolerance. $J$. Appl. Physiol. 92, 2177-2186 (2002).

[12] Hall, D. M., Sattler, G. L., Sattler, C. A., Zhang, H. J., Oberley, L. W., Pitot, H. C. \& Kregel, K. C. Aging lowers steady-state antioxidant enzyme and stress protein expression in primary hepatocytes. J. Gerontol. A Biol. Sci. Med. Sci. 56, B259-267 (2001).

[13] Arnaud, C., Joyeux, M., Garrel, C., Godin-Ribuot, D., Demenge, P. \& Ribuot, C. Free-radical production triggered by hyperthermia contributes to heat stress-induced cardioprotection in isolated rat hearts. Br. J. Pharmacol. 135, 1776$1782(2002)$

[14] Almutawa, F., Thalib, L., Hekman, D., Sun, Q., Hamzavi, I. \& Lim, H. W. Efficacy of localized phototherapy and photodynamic therapy for psoriasis: a systematic review and metaanalysis. Photodermatol. Photoimmunol. Photomed. 31, 5-14 (2013).

[15] Matsuda, M., Hoshino, T., Yamashita, Y., Tanaka, K., Maji, D., Sato, K., Adachi, H., Sobue, G., Ihn, H., Funasaka, Y. \& 
Mizushima, T. Prevention of UVB radiation-induced epidermal damage by expression of heat shock protein 70 . J. Biol. Chem. 285, 5848-5858 (2010).

[16] Wlaschek, M., Tantcheva-Poor, I., Naderi, L., Ma, W., Schneider, L. A., Razi-Wolf, Z., Schuller, J. \& ScharffetterKochanek, K. Solar UV irradiation and dermal photoaging. J. Photochem. Photobiol. B 63, 41-51 (2001).

[17] Yamamoto, S., Takahashi, N. \& Mori, Y. Chemical physiology of oxidative stress-activated TRPM2 and TRPC5 channels. Prog. Biophys. Mol. Biol. 103, 18-27 (2010).

[18] Groschner, K., Rosker, C. \& Lukas, M. Role of TRP channels in oxidative stress. Novartis Found. Symp. 258, 222-230 (2004).

[19] Brookes, P. S., Yoon, Y., Robotham, J.L., Anders, M. W. \& Sheu, S. S. Calcium, ATP, and ROS: a mitochondrial love-hate triangle. Am. J. Physiol. Cell Physiol. 287, C817-833 (2004).

[20] Lennikov, A., Kitaichi, N., Kase, S., Noda, K., Horie, Y., Nakai, A., Ohno, S. \& Ishida, S. Induction of heat shock protein 70 ameliorates ultraviolet-induced photokeratitis in mice. Int. J. Mol. Sci. 14, 2175-2189 (2013).

[21] Perluigi, M., Di Domenico, F., Blarzino, C., Foppoli, C., Cini, C., Giorgi, A., Grillo, C., De Marco, F., Butterfield, D. A., Schinina, M. E. \& Coccia, R. Effects of UVB-induced oxidative stress on protein expression and specific protein oxidation in normal human epithelial keratinocytes: a proteomic approach. Proteome Sci. 8, 13 (2010).

[22] Di Domenico, F., Perluigi, M., Foppoli, C., Blarzino, C., Coccia, R., De Marco, F., Butterfield, D. A. \& Cini, C. Protective effect of ferulic acid ethyl ester against oxidative stress mediated by UVB irradiation in human epidermal melanocytes. Free Radic. Res. 43, 365-375 (2009).

[23] Clapham, D. E. \& Miller, C. A thermodynamic framework for understanding temperature sensing by transient receptor potential (TRP) channels. Proc. Natl. Acad. Sci. USA 108, 19492 19497 (2011).

[24] Mbaya, E., Oules, B., Caspersen, C., Tacine, R., Massinet, H., Pennuto, M., Chretien, D., Munnich, A., Rotig, A., Rizzuto, R., Rutter, G. A., Paterlini-Brechot, P. \& Chami, M. Calcium signalling-dependent mitochondrial dysfunction and bioenergetics regulation in respiratory chain Complex II deficiency. Cell Death Differ. 17, 1855-1866 (2010).

[25] Jekabsone, A., Ivanoviene, L., Brown, G. C. \& Borutaite, V. Nitric oxide and calcium together inactivate mitochondrial complex I and induce cytochrome c release. J. Mol. Cell. Cardiol. 35, 803-809 (2003).

[26] Voets, T., Droogmans, G., Wissenbach, U., Janssens, A., Flockerzi, V. \& Nilius, B. The principle of temperaturedependent gating in cold- and heat-sensitive TRP channels. Nature 430, 748-754 (2004).

[27] Nilius, B., Talavera, K., Owsianik, G., Prenen, J., Droogmans, G. \& Voets, T. Gating of TRP channels: a voltage connection? J. Physiol. 567, 35-44 (2005).

[28] Panzano, V. C., Kang, K. \& Garrity, P. A. Infrared snake eyes: TRPA1 and the thermal sensitivity of the snake pit organ. Sci. Signal. 3, pe22 (2010).

[29] Park, J. H., Lee, S., Cho, D. H., Park, Y. M., Kang, D. H. \& Jo, I. Far-infrared radiation acutely increases nitric oxide production by increasing $\mathrm{Ca}(2+)$ mobilization and $\mathrm{Ca}(2+) /$ calmodulindependent protein kinase II-mediated phosphorylation of endothelial nitric oxide synthase at serine 1179. Biochem. Biophys. Res. Commun. 436, 601-606 (2013).

[30] Sokolovski, S. G., Zolotovskaya, S. A., Goltsov, A., Pourreyron, C., South, A. P. \& Rafailov, E. U. Infrared laser pulse triggers increased singlet oxygen production in tumour cells. Sci. Rep. 3, 3484 (2013).

[31] Gudkov, S. V., Bruskov, V.I., Astashev, M.E., Chernikov,
A. V., Yaguzhinsky, L. S. \& Zakharov, S. D. Oxygen-dependent auto-oscillations of water luminescence triggered by the 1264 nm radiation. J. Phys. Chem. B 115, 7693-7698 (2011).

[32] Lesser, M. P. Oxidative stress in marine environments: biochemistry and physiological ecology. Ann. Rev. Physiol. 68, 253-278 (2006).

[33] Desmet, K. D., Paz, D. A., Corry, J. J., Eells, J. T., WongRiley, M. T., Henry, M. M., Buchmann, E. V., Connelly, M. P., Dovi, J. V., Liang, H. L., Henshel, D. S., Yeager, R. L., Millsap, D. S., Lim, J., Gould, L. J., Das, R., Jett, M., Hodgson, B. D., Margolis, D. \& Whelan, H. T. Clinical and experimental applications of NIR-LED photobiomodulation. Photomed. Laser Surg. 24, 121-128 (2006).

[34] Tanaka, Y., Kawashima, M. \& Nishida, H. The impact of near-infrared in plastic surgery. Plast. Surg. Int. 2013, 1-13 (2013).

[35] Frederiksen, P. K., McIlroy, S. P., Nielsen, C. B., Nikolajsen, L., Skovsen, E., Jorgensen, M., Mikkelsen, K. V. \& Ogilby, P. R. Two-photon photosensitized production of singlet oxygen in water. J. Am. Chem. Soc. 127, 255-269 (2005).

[36] Beck, B., Zholos, A., Sydorenko, V., Roudbaraki, M., Lehen'kyi, V., Bordat, P., Prevarskaya, N. \& Skryma, R. TRPC7 is a receptor-operated DAG-activated channel in human keratinocytes. J. Invest. Dermatol. 126, 1982-1993 (2006).

[37] Vay, L., Gu, C. \& McNaughton, P. A. The thermo-TRP ion channel family: properties and therapeutic implications. Br. J. Pharmacol. 165, 787-801 (2012).

[38] Lan, C. C., Wu, C. S. \& Yu, H. S. Solar-simulated radiation and heat treatment induced metalloproteinase-1 expression in cultured dermal fibroblasts via distinct pathways: implications on reduction of sun-associated aging. J. Dermatol. Sci. 72, 290-295 (2013).

[39] Woo, D. H., Jung, S. J., Zhu, M. H., Park, C. K., Kim, Y. H., Oh, S. B. \& Lee, C. J. Direct activation of transient receptor potential vanilloid 1 (TRPV1) by diacylglycerol (DAG). Mol. Pain 4, 42 (2008).

[40] Sandal, M., Paltrinieri, D., Carloni, P., Musiani, F. \& Giorgetti, A. Structure/function relationships of phospholipases C Beta. Curr. Protein Pept. Sci. 14, 650-657 (2013).

[41] Ramsey, I. S., Delling, M. \& Clapham, D. E. An introduction to TRP channels. Ann. Rev. Physiol. 68, 619-647 (2006).

[42] Chung, M. K., Lee, H., Mizuno, A., Suzuki, M. \& Caterina, M. J. 2-aminoethoxydiphenyl borate activates and sensitizes the heat-gated ion channel TRPV3. J. Neurosci. 24, 51775182 (2004).

[43] Mergler, S., Garreis, F., Sahlmuller, M., Reinach, P. S., Paulsen, F. \& Pleyer, U. Thermosensitive transient receptor potential channels in human corneal epithelial cells. J. Cell. Physiol. 226, 1828-1842 (2011).

[44] Nilius, B. \& Owsianik, G. The transient receptor potential family of ion channels. Genome Biol. 12, 218 (2011).

[45] Donnerer, J. \& Liebmann, I. Phosphorylation of ERK1/2 in dorsal root ganglia following sequential mustard oil and thermal stimulation of the rat hind paw. Pharmacology 89, 7-12 (2012).

[46] Zayats, V., Samad, A., Minofar, B., Roelofs, K. E., Stockner, T. \& Ettrich, R. Regulation of the transient receptor potential channel TRPA1 by its $\mathrm{N}$-terminal ankyrin repeat domain. $J$. Mol. Model. 19, 4689-4700 (2013).

[47] Wilson, S. R., Gerhold, K. A., Bifolck-Fisher, A., Liu, Q., Patel, K. N., Dong, X. \& Bautista, D. M. TRPA1 is required for histamine-independent, Mas-related G protein-coupled receptor-mediated itch. Nat. Neurosci. 14, 595-602 (2011).

[48] Obata, K., Katsura, H., Mizushima, T., Yamanaka, H., Kobayashi, K., Dai, Y., Fukuoka, T., Tokunaga, A., Tominaga, M. \& Noguchi, K. TRPA1 induced in sensory neurons contrib- 
utes to cold hyperalgesia after inflammation and nerve injury. J. Clin. Invest. 115, 2393-2401 (2005).

[49] Bang, S. \& Hwang, S. W. Polymodal ligand sensitivity of TRPA1 and its modes of interactions. J. Gen. Physiol. 133, 257-262 (2009).

[50] Bang, D., Tereshko, V., Kossiakoff, A. A. \& Kent, S. B. Role of a salt bridge in the model protein crambin explored by chemical protein synthesis: $\mathrm{X}$-ray structure of a unique protein analogue, [V15A]crambin-alpha-carboxamide. Mol. Biosyst. 5, 750-756 (2009).

[51] Nagata, K., Duggan, A., Kumar, G. \& Garcia-Anoveros, J. Nociceptor and hair cell transducer properties of TRPA1, a channel for pain and hearing. J. Neurosci. 25, 4052-4061 (2005).

[52] Andrade, E. L., Meotti, F. C. \& Calixto, J. B. TRPA1 antagonists as potential analgesic drugs. Pharmacol. Ther. 133, 189204 (2012).

[53] Bessac, B. F. \& Jordt, S. E. Breathtaking TRP channels: TRPA1 and TRPV1 in airway chemosensation and reflex control. Physiology (Bethesda) 23, 360-370 (2008).

[54] Akopian, A. N., Ruparel, N. B., Jeske, N. A. \& Hargreaves, K. M. Transient receptor potential TRPA1 channel desensitization in sensory neurons is agonist dependent and regulated by TRPV1-directed internalization. J. Physiol. 583, 175-193 (2007).

[55] Behrendt, H. J., Germann, T., Gillen, C., Hatt, H. \& Jostock, R. Characterization of the mouse cold-menthol receptor TRPM8 and vanilloid receptor type-1 VR1 using a fluorometric imaging plate reader (FLIPR) assay. Bri. J. Pharmacol. 141, 737-745 (2004).

[56] Harteneck, C. Function and pharmacology of TRPM cation channels. Naunyn Schmiedebergs Arch. Pharmacol. 371, 307314 (2005).

[57] Gavva, N. R., Davis, C., Lehto, S. G., Rao, S., Wang, W. \& Zhu, D. X. Transient receptor potential melastatin 8 (TRPM8) channels are involved in body temperature regulation. Mol. Pain 8, 36 (2012)

[58] Hardie, R. C. TRP channels and lipids: from Drosophila to mammalian physiology. J. Physiol. 578, 9-24 (2007).

[59] Sakura, H. \& Ashcroft, F. M. Identification of four trp1 gene variants murine pancreatic beta-cells. Diabetologia 40, 528532 (1997).

[60] Beck, B., Lehen'kyi, V., Roudbaraki, M., Flourakis, M., Charveron, M., Bordat, P., Polakowska, R., Prevarskaya, N. \& Skryma, R. TRPC channels determine human keratinocyte differentiation: new insight into basal cell carcinoma. Cell Calcium 43, 492-505 (2008).

[61] Cai, S., Fatherazi, S., Presland, R. B., Belton, C. M. \& Izutsu, K. T. TRPC channel expression during calcium-induced differentiation of human gingival keratinocytes. J. Dermatol. Sci. 40, 21-28 (2005).

[62] Hardie, R. C. Photosensitive TRPs. Handb. Exp. Pharmacol. 223, 795-826 (2014)

[63] Muller, M., Essin, K., Hill, K., Beschmann, H., Rubant, S., Schempp, C. M., Gollasch, M., Boehncke, W. H., Harteneck, C., Muller, W. E. \& Leuner, K. Specific TRPC6 channel activation, a novel approach to stimulate keratinocyte differentiation. J. Biol. Chem. 283, 33942-33954 (2008).

[64] Rome, C., Couillaud, F. \& Moonen, C. T. Spatial and temporal control of expression of therapeutic genes using heat shock protein promoters. Methods 35, 188-198 (2005).

[65] Sankhala, K. K., Mita, M. M., Mita, A. C. \& Takimoto, C. H. Heat shock proteins: a potential anticancer target. Curr. Drug Targets 12, 2001-2008 (2011).

[66] Kim, M. S., Kim, Y. K., Cho, K. H. \& Chung, J. H. Infrared exposure induces an angiogenic switch in human skin that is partially mediated by heat. $\mathrm{Br}$. J. Dermatol. 155, 1131-1138 (2006).

[67] Tang, H., Kobayashi, H., Niidome, Y., Mori, T., Katayama, Y. \& Niidome, T. CW/pulsed NIR irradiation of gold nanorods: effect on transdermal protein delivery mediated by photothermal ablation. J. Control. Release 171, 178-183 (2013).

[68] Jomova, K. \& Morovič, M. Effect of heavy metal treatment on molecular changes in root tips of Lupinus luteus L. Czech J. Food Sci. 27, S386-S389 (2009).

[69] Multhoff, G. \& De Maio, A. Stress down south: meeting report of the fifth International Workshop on the Molecular Biology of Stress Responses. Cell Stress Chaperones 11, 108115 (2006).

[70] De Maio, A. Heat shock proteins: facts, thoughts, and dreams. Shock 11, 1-12 (1999)

[71] Raedschelders, K., Ansley, D. M. \& Chen, D. D. The cellular and molecular origin of reactive oxygen species generation during myocardial ischemia and reperfusion. Pharmacol. Ther. 133, 230-255 (2012).

[72] Oikawa, S., Yamada, T., Minohata, T., Kobayashi, H., Furukawa, A., Tada-Oikawa, S., Hiraku, Y., Murata, M., Kikuchi, M. \& Yamashima, T. Proteomic identification of carbonylated proteins in the monkey hippocampus after ischemia-reperfusion. Free Radic. Biol. Med. 46, 1472-1477 (2009).

[73] Gilbert, H. F. Molecular and cellular aspects of thiol-disulfide exchange. Adv. Enzymol. Relat. Areas Mol. Biol. 63, 69-172 (1990).

[74] McDuffee, A. T., Senisterra, G., Huntley, S., Lepock, J. R., Sekhar, K. R., Meredith, M. J., Borrelli, M. J., Morrow, J. D. \& Freeman, M. L. Proteins containing non-native disulfide bonds generated by oxidative stress can act as signals for the induction of the heat shock response. J. Cell. Physiol. 171, 143-151 (1997).

[75] Graf, R., Schiesser, M., Lussi, A., Went, P., Scheele, G. A. \& Bimmler, D. Coordinate regulation of secretory stress proteins (PSP/reg, PAP I, PAP II, and PAP III) in the rat exocrine pancreas during experimental acute pancreatitis. J. Surg. Res. 105, 136-144 (2002).

[76] Ding, X. Z., Tsokos, G. C. \& Kiang, J. G. Overexpression of HSP-70 inhibits the phosphorylation of HSF1 by activating protein phosphatase and inhibiting protein kinase $\mathrm{C}$ activity. FASEB J. 12, 451-459 (1998).

[77] Liu, H. T., Gao, F., Cui, S. J., Han, J. L., Sun, D. Y. \& Zhou, R. G. Primary evidence for involvement of IP3 in heat-shock signal transduction in Arabidopsis. Cell Res. 16, 394-400 (2006).

[78] Kiang, J. G. \& Tsokos, G. C. Heat shock protein 70 kDa: molecular biology, biochemistry, and physiology. Pharmacol. Ther. 80, 183-201 (1998).

[79] Katusic, Z. S. \& Stelter, A. M. Type I inositol-triphosphate receptor gene is alternatively spliced in human cerebral arteries. Biochem. Biophys. Res. Commun. 214, 803-809 (1995). 